\title{
Conditional Disease-Free and Overall Survival of 1,858 Young Women with Non-Metastatic Breast Cancer and with Participation in a Post-Therapeutic Rehab Programme according to Clinical Subtypes
}

\author{
$J_{\text {Jonathan Pruessmann }}^{a}$ Telja Pursche ${ }^{b, c}$ Friederike Hammersen ${ }^{a}$ \\ Alexander Katalinic ${ }^{a, d}$ Dorothea Fischer ${ }^{e}$ Annika Waldmann ${ }^{a, f}$ \\ ${ }^{a}$ Institute for Social Medicine and Epidemiology, Lübeck University, Lübeck, Germany; ${ }^{b}$ Department of Gynaecology \\ and Obstetrics, University Hospital Schleswig-Holstein, Lübeck, Germany; ' Department of Gynaecology and \\ Obstetrics, Hospital Düren gem. GmbH, Düren, Germany; ${ }^{d}$ Cancer Registry Schleswig-Holstein, Lübeck, Germany; \\ e Department of Gynaecology and Obstetrics, Hospital Ernst von Bergmann, Potsdam, Germany; ${ }^{\mathrm{f} H a m b u r g}$ Cancer \\ Registry, Hamburg, Germany
}

\section{Keywords}

Survival · Non-metastatic breast cancer · Young adults

\begin{abstract}
Background: Breast cancer in young women is associated with unfavourable tumour biology and is the main cause of death in this group. Conditional survival analysis estimates survival rates under the pre-condition of already having survived a certain time. Objectives: To describe conditional disease-free and overall survival of female breast cancer patients according to clinical subtypes and age. Methods: This study analyses information from 1,858 breast cancer patients aged between 21 and 54 years, who were taking part in a post-therapeutic rehab programme (time between diagnosis and rehab start: maximum 24, median 11 months). Mean follow-up time was 3.6 years. We describe biological, clinical and pathological features in regard to different age groups ( $<40$ and $\geq 40$ years) and report conditional 5 -year survival rates for overall and disease-free survival, and Cox proportional hazard models. Results: Very young and young patients differed in regard to hormone receptor negativity, tumour grade, lymphovascular invasion, and molecular sub-
\end{abstract}

types. Young women bore triple-negative and HER2-like disease more frequently. Conditional 5-year overall survival did not differ substantially between women $<40$ and 40-54 years of age ( 95 vs. $96 \%$ ). It was highest for women with cancer of the luminal A subtype (98\%) and lowest for the triplenegative subtype (91\%). Lymphangiosis was a significant predictor of death. Results for disease-free survival were comparable. Conclusions: Conditional 5-year overall survival after non-metastatic breast cancer was as high as $95.5 \%$, and disease-free survival was $85.2 \%$. When controlling for time between diagnosis and rehab start, molecular subtypes influenced overall and disease-free survival prospects. When additionally controlling for clinical characteristics, this effect only remained stable for disease-free survival.

(C) 2020 S. Karger AG, Basel

\section{Introduction}

With 69,000 new cases and a median age of 64 years at diagnosis in 2014, breast cancer among women is still the most frequent type of malignancies in Germany. Survival after breast cancer has recently increased due to new 
treatment strategies and early detection measures. Nowadays, the overall absolute 5-year survival rate is estimated to be as high as $88 \%$ (irrespective of age and stage at diagnosis) [1]. However, as many breast cancer patients die shortly after diagnosis, this overall survival rate may be too pessimistic for cancer survivors. Conditional survival analysis takes survivorship into account and estimates survival rates under the pre-condition that patients have already survived a certain time period.

Approximately 7-9\% of all cancer cases are diagnosed in women $<40$ years with an accumulative lifetime-risk to contract cancer of $0.45 \%$ [1-4]. Based on the GLOBOCAN 2012 data, Fidler et al. [5] estimated recently that about $30.2 \%$ of all cancers occurring in women aged 20 39 years are malignant neoplasms of the breast. This proportion equals an amount of about 191,100 incident cases worldwide. Breast cancer in young women is associated with advanced stage at diagnosis and unfavourable tumour biology and worse pathological features [3, 6-10]. Young breast cancer patients have an increased risk for lymphovascular invasion, oestrogen and progesterone receptor negativity, as well as a higher expression of proliferation marker Ki67 and growth factor HER2 [4, 9, $11-$ 14].

Due to these disadvantageous tumour characteristics, young women proved to be at increased risk for local and systemic recurrences. For example, compared to an age group $>40$, young women show both a worse 5 -year disease-free survival and a worse 5-year overall survival [2, $15,16]$. Although breast cancer in young women $<40$ years is rather rare, it is the most common cause of death in this age group [17]. It was estimated recently, that about $25 \%$ of all cancer-related deaths occurring in women aged 20-39 years are due to malignant neoplasms of the breast (equalling an estimated amount of about 48,775 deaths worldwide) [5].

Many studies suggest a link between tumour subtypes and young age at the time of diagnosis concerning survival $[11,13,14,18]$. The triple-negative subtype, which is associated with worse outcomes and presents itself more often in young women than it does in older women, exemplifies this. In contrast, luminal A disease, which is associated with better outcomes, is more frequently found in older women $[11,13,14]$. As there is no indication for consistent evidence in recent studies and insufficient Germany-specific data, we analysed data of 1,858 young breast cancer patients and aimed to describe tumour characteristics like tumour stage, grading, receptor status, and molecular subtypes. As our study cohort consists of women who participated in a rehab programme which started after initial treatment was terminated (maximum of 2 years after diagnosis), we analysed conditional 5-year overall and disease-free survival for subgroups according to tumour characteristics and age.
Table 1. Definition of tumour subtypes by clinical features according to Brouckaert et al. [19]

\begin{tabular}{llllll}
\hline & ER & PR & HER2 & $\begin{array}{l}\text { Ki67 (if } \\
\text { available) }\end{array}$ & $\begin{array}{l}\text { Grading (if } \\
\text { Ki67 missing) }\end{array}$ \\
\hline Luminal A & + & $+/-$ & - & $<14 \%$ & $<3$ \\
Luminal B1 & + & $+/-$ & - & $\geq 14 \%$ & 3 \\
Luminal B2 & + & $+/-$ & + & & All values \\
HER2 like & - & - & + & & \\
Triple-negative & - & - & - & & \\
\hline
\end{tabular}

\section{Materials and Methods}

\section{Study Population}

This study is a sub-study of a larger cohort study which started in 2009 [6]. The cohort study includes young mothers with nonmetastatic breast cancer who participate in a 3-week in-patient mother-child rehabilitation programme. To be eligible for the programme, the patient's child had to be under the age of 12 and the patient's primary cancer treatment had to be concluded at least 6 weeks prior to the start of the rehab programme. Women with distant metastases at diagnosis were not eligible for the rehab programme and were thus not included in our analysis.

The present study comprises data from 1,858 women aged between 21 and 54 years with invasive non-metastatic breast cancer (ICD-10 code C50 or D05). They took part in the rehab programme between 2010 and 2017 which started within a maximum timespan of 24 months after diagnosis. All women resided in Germany; there was no evidence that women from a particular region or a particular federal state were overrepresented in our study cohort.

\section{Data Sources}

Sociodemographic and basic clinical data were provided by the patients. These data were supplemented by data derived from patient record files. Tumour specimens had been worked up locally at the time of diagnosis. A further centralised work-up of the tumour material at the time of recruitment was not conducted. That is, information on tumour biology and pathology was derived from patient's record files as well.

Follow-up information was provided by the women themselves (e.g., on recurrences or metastasis) in the years 2015 and 2018. The study questionnaire included a question on tumour-related changes after the end of the rehab stay (i.e., local recurrence in the same breast, a tumour in the contralateral breast, local or distant metastasis) and on the date of diagnosis of the disease progression. Additionally, the respective registration offices provided the information whether a woman was alive or dead, including date of death. In case the woman had moved, the office provided the updated address, thus allowing to contact the new corresponding registration office. Vital status was obtained, if applicable, in 2011, 2013, 2015 and winter 2017/2018.

\section{Statistics}

We defined subgroups as follows: tumour subtypes were classified as luminal A, luminal B1, luminal B2, HER2 like, and triplenegative following subtype categories by Brouckaert et al. [19] (Table 1). Further, "very young" women were in the age-range 21-39 years, while "young" women were $40-54$ years old. Hormone receptors and growth factor HER2 were divided in positive and negative. Tumour size was subdivided into 3 groups (Tis/T0/T1; T2; $\mathrm{T} 3 / \mathrm{T} 4)$. Infiltration of regional lymph nodes was divided into 3 groups (N0; N1; N2/N3) and the grading was classified as "low" 
(G1), “intermediate" (G2), "high" (G3), and "missing” (Gx). Finally, we differentiated women who started their rehab programme within the first year from those who started it within 13-24 months after diagnosis.

We used absolute and relative frequencies to describe the overall cohort and age-specific subgroups and $\chi^{2}$ tests to assess statistically significant differences between the age groups.

For deceased patients, survival time was measured as days from the date of diagnosis up to the date of death from any cause. Alive patients were censored at the date of the last follow-up contact (follow-up survey or information from the registration office). As women in our cohort had survived already a certain time (time interval between diagnosis and rehab start) before they entered the study the reported survival rates are conditional survival rates. The latter describe the further survival probability given that a patient has already survived a specific time period.

We present conditional 5-year survival for overall and diseasefree survival stratified by molecular subtypes, age, stage, and tumour characteristics.

Cox proportional hazard models were computed to describe the impact of tumour subtypes, age, tumour characteristics (stage, grading, lymphangiosis, and receptor status) on overall survival/ death and disease-free survival. In the first step of our analysis, we ran several models with death as the dependent variable and each clinical factor as the independent variable while adjusting for the time period between diagnosis and rehab start to control for survivorship bias (model 1). In the second step (model 2), we ran a full model and included age, tumour subtypes, stage, grading, and lymphangiosis as potential clinical predictors while still adjusting for the time period. Hazard ratios (HR) and $95 \%$ confidence intervals (CIs) are reported.

For the analysis, SPSS software version 22 and R (version 4.2.1) with the package periodR were used $[20,21]$. All $p$ values reported are two-sided and were considered to be statistically significant if $<0.05$.

\section{Results}

\section{Patient Characteristics}

The study population consisted of 1,858 young women with a mean age of 39.6 years (SD 5.6, range 21-54) of whom $49.6 \%$ were younger than 40 years and $50.4 \%$ were 40 years or older. Of all women, $63.3 \%$ started their rehab programme within the first year after diagnosis with the median time span between diagnosis and rehab start being 11 months. Women aged $<40$ years were slightly more likely when compared to women aged $40-54$ years to start their rehab programme within the second year after diagnosis ( 38.5 vs. $34.9 \%, p=0.103$ ), but the median time span between diagnosis and rehab start was 11 months for both subgroups. Characteristics of our study cohort, overall and divided by age group, are shown in Table 2. Very young women showed less favourable tumour characteristics compared to young women: Cancer cases of the very young women $(<40$ years) proved to be poorly differentiated. In addition, they presented oestrogen negative or progesterone negative more frequently than the older age group. In contrast, the growth factor HER2 was more fre- quently positive in very young patients. This translates to a lower proportion of luminal A subtype, and a higher proportion of the triple-negative and HER2-like subtype in very young women. Most of the described differences were of statistical significance.

\section{Deaths during Follow-Up}

Median follow-up time was 3.6 years (range 81 days to 8 years since diagnosis). Overall, $3.8 \%(70 / 1,858)$ of nonmetastatic breast cancer patients died during follow-up. The first death occurred 14 months after the rehab programme had been started.

When data were stratified according to tumour biology, the percentage of deaths ranged between 2.1\% (luminal A subtype) and $7.3 \%$ (triple-negative subtype). Stratification by age and time between diagnosis and rehab start, respectively, revealed that the percentage of deaths was higher in the group of very young women $(4.2 \%)$ than in the older group $(3.3 \% ; p=0.295)$ and that the percentage of deaths was lower in the group of women with an early start of the rehab programme compared to women with rehab start $13-24$ months after diagnosis (3.5 vs. $4.3 \%$; $p=0.403$ ).

\section{Survival Analysis}

The 5-year conditional overall survival rate (COS) of women who participated in the rehab programme was $95.5 \%$ as shown in Table 3, and 5-year conditional disease-free survival (DFS) was $85.2 \%$ (Table 4 ).

Taking the time period between diagnosis and rehab start into account, the 5-year COS for women starting the rehab in the first year after diagnosis was lower (94.7 vs. $96.6 \%)$, and the DFS was higher (86.4 vs. $84.2 \%$ ) than for women who had already survived another year since diagnosis and who started the rehab 13-24 months after diagnosis. The younger age group proved to be associated with worse 5-year COS (94.9 vs. 96.1\%) as well as worse 5-year DFS (83.9 vs. $86.5 \%$ ) as compared to the older age group. Among the tumour subtypes, triple-negative disease showed the worst 5-year survival rates (COS 94.4\%; DFS $78.6 \%)$. The 5-year survival rates were worse in advanced tumours than in tumours with modest growth for conditional overall survival (T2: $94.8 \%$, T3 or T4: 86.0 vs. $96.7 \%$, reference group) and for disease-free survival (T2: $85.0 \%$, T3 or T4: 75.3 vs. $85.9 \%$, reference group). Patients with regional lymph node category $\mathrm{N} 2$ or $\mathrm{N} 3$ showed an inferior 5-year survival rate for both, COS (89.3\%) and DFS (77.0\%) when compared to patients without infiltration (COS: 97.5\%; DFS: $87.6 \%$, reference group) and patients with lymphangiosis had inferior 5-year survival rates (COS 92.3\%; DFS $80.3 \%$ ) when compared with to patients without lymphangiosis (COS 97.1\%; DFS 88.3\%). Finally, we observed a lower 5-year COS and DFS for less differentiated tumours (G3; COS 93.5\%; DFS 81.5\%) compared to differentiated tumours (G1; COS 97.3\%; DFS 85.7\%; Tables 3, 4). 
Table 2. Tumour characteristics of young women with breast cancer in Germany overall and according to age groups

\begin{tabular}{|c|c|c|c|c|}
\hline & $\begin{array}{l}\text { Overall } \\
1,858(100)\end{array}$ & $\begin{array}{l}<40 \text { years } \\
921(49.6)\end{array}$ & $\begin{array}{l}\geq 40 \text { years } \\
937(50.4)\end{array}$ & $\begin{array}{l}p \text { value } \\
\left(\chi^{2}\right)\end{array}$ \\
\hline \multicolumn{5}{|l|}{ Primary tumour (T) } \\
\hline Tis & $69(3.7)$ & $29(3.1)$ & $40(3.9)$ & $0.168^{*}$ \\
\hline T0 & $208(11.2)$ & 137 (14.9) & $71(3.3)$ & \\
\hline $\mathrm{T} 1$ & $851(45.8)$ & $407(44.2)$ & $444(49.3)$ & \\
\hline $\mathrm{T} 2$ & $603(32.5)$ & $282(30.6)$ & $321(37.0)$ & \\
\hline T3 & $91(4.9)$ & $45(4.9)$ & $46(5.2)$ & \\
\hline $\mathrm{T} 4$ & $8(0.4)$ & $3(0.3)$ & $5(0.9)$ & \\
\hline Tx (unknown) & $28(1.5)$ & $18(2.0)$ & $10(0.4)$ & \\
\hline \multicolumn{5}{|c|}{ Regional lymph nodes (N) } \\
\hline No & $1,127(60.7)$ & $567(61.6)$ & $560(59.8)$ & 0.827 \\
\hline N1 & $488(26.3)$ & $234(25.4)$ & $254(27.1)$ & \\
\hline N2 & $141(7.6)$ & $67(7.3)$ & $74(7.9)$ & \\
\hline N3 & $65(3.5)$ & $34(3.7)$ & $31(3.3)$ & \\
\hline Nx (unknown) & $37(2.0)$ & $19(2.1)$ & $18(1.9)$ & \\
\hline \multicolumn{5}{|l|}{ Histologic grade } \\
\hline 1 & $106(5.7)$ & $46(5.0)$ & $60(6.4)$ & $<0.001$ \\
\hline 2 & $800(43.1)$ & $343(37.2)$ & $457(48.4)$ & \\
\hline 3 & $844(45.4)$ & $484(52.6)$ & $360(38.4)$ & \\
\hline Gx (unknown) & $108(5.8)$ & $48(5.2)$ & $60(6.4)$ & \\
\hline \multicolumn{5}{|l|}{ ER status } \\
\hline Positive & $1,298(69.9)$ & $570(61.9)$ & $728(77.7)$ & $<0.001$ \\
\hline Negative & $548(29.5)$ & $348(37.8)$ & $200(21.3)$ & \\
\hline Unknown & $12(0.6)$ & $3(0.3)$ & $9(1.0)$ & \\
\hline \multicolumn{5}{|l|}{ PR status } \\
\hline Positive & $1,171(63.1)$ & $507(55.0)$ & $664(70.9)$ & $<0.001$ \\
\hline Negative & $670(36.1)$ & $409(44.4)$ & $261(27.9)$ & \\
\hline Unknown & $16(0.9)$ & $5(0.5)$ & $11(1.2)$ & \\
\hline \multicolumn{5}{|l|}{ HER2 status } \\
\hline Positive & $491(26.4)$ & $281(30.5)$ & $210(22.4)$ & 0.001 \\
\hline Negative & $1,319(71.0)$ & $623(67.7)$ & $696(74.3)$ & \\
\hline Unknown & $47(2.5)$ & $16(1.7)$ & $31(3.3)$ & \\
\hline \multicolumn{5}{|l|}{ Lymphangiosis } \\
\hline Yes & $434(23.4)$ & $227(24.6)$ & $207(22.1)$ & 0.197 \\
\hline No & $1,141(61.4)$ & $547(59.4)$ & $594(63.5)$ & \\
\hline Unknown & $282(15.2)$ & $147(16.0)$ & $135(14.4)$ & \\
\hline \multicolumn{5}{|l|}{ Tumour subtype } \\
\hline Luminal A & $607(32.7)$ & $223(24.2)$ & $384(41.0)$ & $<0.001$ \\
\hline Luminal B1 & $275(14.8)$ & $126(13.7)$ & 149 (15.9) & \\
\hline Luminal B2 & $347(18.7)$ & $188(20.4)$ & $159(17.0)$ & \\
\hline HER2 like & $129(6.9)$ & $81(8.8)$ & $48(5.1)$ & \\
\hline Triple-negative & $368(19.8)$ & $235(25.5)$ & $133(14.2)$ & \\
\hline Unknown & $132(7.1)$ & $68(7.4)$ & $64(6.8)$ & \\
\hline
\end{tabular}

Data are presented as $n(\%) .{ }^{*}$ Grouped T categories Tis/T0/T1 vs. T2 vs. T3/T4 vs. unknown were used for $\chi^{2}$ test.

Univariate Cox proportional hazard regression analyses indicated that conditional overall survival and conditional disease-free survival prospects were altered by the time between diagnosis and rehab start: the hazard to die during follow-up was increased for those who started their rehab during the early phase after diagnosis and treatment as compared to those who had already survived for 2 years (i.e., for COS HR 1.55, 95\% CI 0.94-2.57, $p=$ 0.087; for DFS HR 1.95, 95\% CI 1.40-2.71, $p<0.001$ ). Thus, all further regression models included time between diagnosis and rehab start as a confounding variable. 
Table 3. Conditional 1-, 3-, and 5-year observed overall survival (COS) with corresponding standard errors (SE), and hazard risks for death (HR) with corresponding 95\% confidence intervals (95\% CI)

\begin{tabular}{|c|c|c|c|c|c|c|c|c|c|c|c|c|c|}
\hline \multirow[t]{2}{*}{ Category } & \multirow{2}{*}{$\begin{array}{l}\text { Women, } \\
n\end{array}$} & \multirow{2}{*}{$\begin{array}{l}1 \text {-year } \\
\text { COS }\end{array}$} & \multirow{2}{*}{ SE } & \multirow{2}{*}{$\begin{array}{l}3 \text {-year } \\
\text { COS }\end{array}$} & \multirow[t]{2}{*}{ SE } & \multirow{2}{*}{$\begin{array}{l}5 \text {-year } \\
\text { COS }\end{array}$} & \multirow[t]{2}{*}{ SE } & \multirow{2}{*}{$\begin{array}{l}\text { Model 1: } \\
\mathrm{HR}^{1}\end{array}$} & \multicolumn{2}{|c|}{$95 \% \mathrm{CI}$} & \multirow{2}{*}{$\begin{array}{l}\text { Model 2: } \\
\mathrm{HR}^{1}\end{array}$} & \multicolumn{2}{|c|}{$95 \% \mathrm{CI}$} \\
\hline & & & & & & & & & lower & upper & & lower & upper \\
\hline Overall & 1,858 & 100 & 0 & 97.5 & 0.4 & 95.5 & 0.6 & & & & & & \\
\hline \multicolumn{14}{|c|}{ Time between diagnosis and rehab start } \\
\hline 13-24 months & 682 & 100 & 0 & 98.4 & 0.5 & 96.6 & 0.8 & & & & & & \\
\hline$\leq 12$ months & 1,176 & 100 & 0 & 96.9 & 0.6 & 94.7 & 0.9 & & & & & & \\
\hline \multicolumn{14}{|l|}{ Age } \\
\hline$\geq 40$ years & 937 & 100 & 0 & 98.0 & 0.5 & 96.1 & 0.8 & Ref. & & & Ref. & & \\
\hline$<40$ years & 921 & 100 & 0 & 97.1 & 0.6 & 94.9 & 0.9 & 1.34 & 0.84 & 2.15 & 1.07 & 0.65 & 1.75 \\
\hline \multicolumn{14}{|l|}{ Tumour subtype } \\
\hline Luminal A & 607 & 100 & 0 & 99.2 & 0.4 & 98.0 & 0.7 & Ref. & & & Ref. & & \\
\hline Luminal B1 & 275 & 100 & 0 & 97.6 & 1.1 & 95.6 & 1.5 & 2.41 & 1.10 & 5.30 & 1.15 & 0.36 & 3.74 \\
\hline Luminal B2 & 347 & 100 & 0 & 97.9 & 0.9 & 96.4 & 1.4 & 2.09 & 0.95 & 4.59 & 1.36 & 0.51 & 3.61 \\
\hline HER2 like & 129 & 100 & 0 & 97.6 & 1.7 & 95.5 & 2.6 & 1.40 & 0.40 & 4.92 & 1.00 & 0.23 & 4.28 \\
\hline Triple- negative & 368 & 100 & 0 & 94.4 & 1.4 & 90.5 & 1.9 & 3.88 & 1.99 & 7.55 & 2.58 & 0.90 & 7.46 \\
\hline \multicolumn{14}{|l|}{ ER status } \\
\hline Positive & 1,298 & 100 & 0 & 98.4 & 0.4 & 96.9 & 0.6 & Ref. & & & - & & \\
\hline Negative & 548 & 100 & 0 & 95.3 & 1.1 & 92.1 & 1.5 & 1.96 & 1.22 & 3.16 & & & \\
\hline \multicolumn{14}{|l|}{ PR status } \\
\hline Positive & 1,171 & 100 & 0 & 99.0 & 0.3 & 97.9 & 0.6 & Ref. & & & - & & \\
\hline Negative & 670 & 100 & 0 & 94.9 & 1.0 & 91.5 & 1.4 & 2.81 & 1.73 & 4.57 & & & \\
\hline \multicolumn{14}{|l|}{ HER2 status } \\
\hline Positive & 491 & 100 & 0 & 97.8 & 0.8 & 96.3 & 1.2 & Ref. & & & - & & \\
\hline Negative & 1,319 & 100 & 0 & 97.3 & 0.5 & 95.1 & 0.7 & 1.15 & 0.65 & 2.04 & & & \\
\hline \multicolumn{14}{|l|}{ Lymphangiosis } \\
\hline Yes & 4,434 & 100 & 0 & 96.7 & 1.0 & 92.3 & 1.6 & Ref. & & & Ref. & & \\
\hline No & 1,141 & 100 & 0 & 98.2 & 0.5 & 97.1 & 0.6 & 0.42 & 0.25 & 0.69 & 0.53 & 0.30 & 0.93 \\
\hline \multicolumn{14}{|l|}{ Primary tumour } \\
\hline Tis/T0/T1 & 1,128 & 100 & 0 & 98.4 & 0.5 & 96.7 & 0.7 & Ref. & & & Ref. & & \\
\hline $\mathrm{T} 2$ & 603 & 100 & 0 & 96.6 & 0.8 & 94.8 & 1.1 & 1.42 & 0.83 & 2.41 & 1.42 & 0.83 & 2.41 \\
\hline $\mathrm{T} 3 / \mathrm{T} 4$ & 99 & 100 & 0 & 93.8 & 2.7 & 86.0 & 4.5 & 2.21 & 0.98 & 4.97 & 2.22 & 0.98 & 5.00 \\
\hline \multicolumn{14}{|c|}{ Regional lymph nodes } \\
\hline No & 1,127 & 100 & 0 & 98.6 & 0.4 & 97.5 & 0.6 & Ref. & & & Ref. & & \\
\hline $\mathrm{N} 1$ & 488 & 100 & 0 & 96.7 & 0.9 & 93.8 & 1.4 & 1.65 & 0.93 & 2.93 & 1.65 & 0.92 & 2.94 \\
\hline $\mathrm{N} 2 / \mathrm{N} 3$ & 206 & 100 & 0 & 93.9 & 1.9 & 89.3 & 2.6 & 2.06 & 1.01 & 4.19 & 2.03 & 0.99 & 4.14 \\
\hline \multicolumn{14}{|l|}{ Histologic grade } \\
\hline G1 & 106 & 100 & 0 & 97.3 & 1.9 & 97.3 & 1.9 & Ref. & & & Ref. & & \\
\hline $\mathrm{G} 2$ & 800 & 100 & 0 & 99.3 & 0.3 & 97.6 & 0.7 & 1.20 & 0.28 & 5.16 & 0.78 & 0.18 & 3.42 \\
\hline G3 & 844 & 100 & 0 & 96.0 & 0.8 & 93.5 & 1.1 & 3.20 & 0.78 & 13.2 & 1.64 & 0.32 & 8.50 \\
\hline
\end{tabular}

${ }^{1}$ The multivariate model 1 included time period between diagnosis and rehab start (as continuous variable) to correct for survivorship bias. Model 2 additionally included age groups, tumour biology, lymphangiosis, $\mathrm{T}$ and $\mathrm{N}$ category, and histologic grade as predictor variables.

All effect estimators were comparable in size, direction, and statistical significance (the only exception: tumour categories $\mathrm{T} 2$ and $\mathrm{T} 3 / \mathrm{T} 4$ were significant predictors of DFS but not of COS) in regression analyses with either disease-free or overall survival as the dependent variable (model 1; Tables 3, 4).
The results of the multivariate analysis with the fully adjusted model 2 on COS confirmed, in principle, the results from the analysis adjusted only for time between diagnosis and rehab start (model 1), but all effect estimators found to be statistically significant in model 1 analyses (i.e., those for progressed lymph node infiltration, tumour biology luminal B1 and triple-negative) lost statistical significance in the 
Table 4. Conditional 1-, 3-, and 5-year disease-free survival (DFS) with corresponding standard errors (SE), and hazard risks for death (HR) with corresponding 95\% confidence intervals (95\% CI)

\begin{tabular}{|c|c|c|c|c|c|c|c|c|c|c|c|c|c|}
\hline \multirow[t]{2}{*}{ Category } & \multirow{2}{*}{$\begin{array}{l}\text { Women, } \\
n\end{array}$} & \multirow{2}{*}{$\begin{array}{l}1 \text {-year } \\
\text { DFS }\end{array}$} & \multirow[t]{2}{*}{ SE } & \multirow{2}{*}{$\begin{array}{l}3 \text {-year } \\
\text { DFS }\end{array}$} & \multirow{2}{*}{ SE } & \multirow{2}{*}{$\begin{array}{l}5 \text {-year } \\
\text { DFS }\end{array}$} & \multirow[t]{2}{*}{ SE } & \multirow{2}{*}{$\begin{array}{l}\text { Model 1: } \\
\mathrm{HR}^{1}\end{array}$} & \multicolumn{2}{|c|}{$95 \% \mathrm{CI}$} & \multirow{2}{*}{$\begin{array}{l}\text { Model 2: } \\
\mathrm{HR}^{1}\end{array}$} & \multicolumn{2}{|c|}{$95 \% \mathrm{CI}$} \\
\hline & & & & & & & & & lower & upper & & lower & upper \\
\hline Overall & 1,858 & 99.6 & 0.2 & 92.9 & 0.7 & 85.2 & 1.1 & & & & & & \\
\hline \multicolumn{14}{|c|}{ Time between diagnosis and rehab start } \\
\hline $13-24$ months & 682 & 99.7 & 0.2 & 93.1 & 1.1 & 84.2 & 1.6 & & & & & & \\
\hline$\leq 12$ months & 1,176 & 99.5 & 0.2 & 92.7 & 0.9 & 86.4 & 1.4 & & & & & & \\
\hline \multicolumn{14}{|l|}{ Age } \\
\hline$\geq 40$ years & 937 & 99.8 & 0.2 & 93.3 & 0.9 & 86.5 & 1.5 & Ref. & & & Ref. & & \\
\hline$<40$ years & 921 & 99.4 & 0.3 & 92.4 & 1.0 & 83.9 & 1.6 & 1.29 & 0.97 & 1.72 & 1.13 & 0.84 & 1.52 \\
\hline \multicolumn{14}{|l|}{ Tumour subtype } \\
\hline Luminal A & 607 & 99.5 & 0.3 & 96.1 & 0.9 & 90.3 & 1.5 & Ref. & & & Ref. & & \\
\hline Luminal B1 & 275 & 99.2 & 0.5 & 91.6 & 1.9 & 81.9 & 3.1 & 2.05 & 1.31 & 3.19 & 1.59 & 0.82 & 3.11 \\
\hline Luminal B2 & 347 & 100 & 0 & 93.9 & 1.6 & 87.4 & 2.5 & 1.52 & 0.95 & 2.41 & 1.28 & 0.74 & 2.21 \\
\hline HER2 like & 129 & 99.2 & 0.8 & 93.4 & 2.6 & 83.8 & 4.7 & 1.63 & 0.86 & 3.08 & 1.53 & 0.74 & 3.17 \\
\hline Triple-negative & 368 & 99.7 & 0.3 & 87.3 & 2.0 & 78.6 & 2.7 & 2.42 & 1.65 & 3.55 & 2.14 & 1.18 & 3.38 \\
\hline \multicolumn{14}{|l|}{ ER status } \\
\hline Positive & 1,298 & 99.6 & 0.2 & 94.2 & 0.8 & 86.8 & 1.3 & Ref. & & & - & & \\
\hline Negative & 548 & 99.6 & 0.3 & 89.4 & 1.5 & 81.3 & 2.2 & 1.48 & 1.10 & 1.98 & & & \\
\hline \multicolumn{14}{|l|}{ PR status } \\
\hline Positive & 1,171 & 99.5 & 0.2 & 95.1 & 0.7 & 88.8 & 1.2 & Ref. & & & - & & \\
\hline Negative & 670 & 99.7 & 0.2 & 88.8 & 1.4 & 78.9 & 2.0 & 1.89 & 1.42 & 2.51 & & & \\
\hline \multicolumn{14}{|l|}{ HER2 status } \\
\hline Positive & 491 & 99.8 & 0.2 & 93.9 & 1.3 & 86.8 & 2.1 & Ref. & & & - & & \\
\hline Negative & 1,319 & 99.5 & 0.2 & 92.5 & 0.8 & 84.6 & 1.3 & 1.09 & 0.77 & 1.54 & & & \\
\hline \multicolumn{14}{|l|}{ Lymphangiosis } \\
\hline Yes & 434 & 99.8 & 0.2 & 91.6 & 1.5 & 80.3 & 2.5 & Ref. & & & Ref. & & \\
\hline No & 1,141 & 99.4 & 0.2 & 94.1 & 0.8 & 88.3 & 1.2 & 0.52 & 0.38 & 0.72 & 0.58 & 0.40 & 0.82 \\
\hline \multicolumn{14}{|l|}{ Primary tumour } \\
\hline Tis/T0/T1 & 1,128 & 99.7 & 0.2 & 94.2 & 0.8 & 85.9 & 1.4 & Ref. & & & Ref. & & \\
\hline $\mathrm{T} 2$ & 603 & 99.3 & 0.3 & 90.9 & 1.3 & 85.0 & 1.8 & 1.35 & 1.00 & 1.81 & 1.22 & 0.89 & 1.67 \\
\hline $\mathrm{T} 3 / \mathrm{T} 4$ & 99 & 100 & 0 & 88.3 & 3.7 & 75.3 & 5.5 & 1.82 & 1.07 & 3.09 & 1.39 & 0.79 & 2.45 \\
\hline \multicolumn{14}{|c|}{ Regional lymph nodes } \\
\hline No & 1,127 & 99.7 & 0.2 & 93.5 & 0.9 & 87.6 & 1.3 & Ref. & & & Ref. & & \\
\hline N1 & 488 & 99.4 & 0.4 & 93.1 & 1.3 & 83.6 & 2.2 & 1.28 & 0.92 & 1.79 & 1.15 & 0.81 & 1.64 \\
\hline $\mathrm{N} 2 / \mathrm{N} 3$ & 206 & 99.5 & 0.5 & 88.4 & 2.5 & 77.0 & 3.6 & 2.04 & 1.41 & 2.95 & 1.76 & 1.15 & 2.69 \\
\hline \multicolumn{14}{|l|}{ Histologic grade } \\
\hline 1 & 106 & 99.0 & 1.0 & 93.7 & 2.8 & 85.7 & 4.6 & Ref. & & & Ref. & & \\
\hline 2 & 800 & 99.7 & 0.2 & 96.5 & 0.7 & 90.1 & 1.4 & 0.93 & 0.46 & 1.87 & 0.65 & 0.32 & 1.32 \\
\hline 3 & 844 & 99.5 & 0.2 & 89.7 & 1.2 & 81.5 & 1.7 & 1.75 & 0.89 & 3.45 & 0.86 & 0.38 & 1.95 \\
\hline
\end{tabular}

${ }^{1}$ The multivariate model 1 included time period between diagnosis and rehab start (as continuous variable) to correct for survivorship bias. Model 2 additionally included age groups, tumour biology, lymphangiosis, $\mathrm{T}$ and $\mathrm{N}$ category, and histologic grade as predictor variables.

full model (Table 3). The only clinical factor that remained as a significant predictor in both models was lymphangiosis (model 1 HR 0.42 and model 2 HR 0.53 for the group without lymphangiosis when compared to the group with lymphangiosis). The results for DFS were comparable, but advanced regional lymph node involvement $(\mathrm{N} 2, \mathrm{~N} 3)$ remained in addition as a significant predictor in the model.

\section{Discussion/Conclusion}

Breast cancer in very young women is associated with unfavourable tumour characteristics and worse outcomes $[2,3,6,11-16]$. As the literature on young breast cancer patients in Germany is relatively sparse, we assessed 5 -year conditional overall and disease-free survival of 
1,858 young women with non-metastatic breast cancer stratified by tumour biology and further clinical characteristics. Further, we wanted to explore whether age had an additional effect on survival in our young cohort and thus stratified our sample into "very young" ( $<40$ years) and "young" women (40-54 years of age). Finally, we aimed to identify predictors for death during the followup period.

In brief, the main findings are:

1. In our study population, observed 5-year conditional overall survival is as high as $95.5 \%$ and 5-year diseasefree survival equals $85.2 \%$. In the group of women who started rehab within 12 months after diagnosis, survival was lower than in women who started rehab 13 24 months after diagnosis.

2. Molecular subtypes and biological, pathological, and clinical characteristics that are associated with poorer prognosis are more frequently found in very young ( $<40$ years) than in young breast cancer patients $(40-$ 54 years).

3. In addition to known risk factor for poor survival such as advanced infiltration of regional lymph nodes, lymphangiosis, and triple-negative subtype proved to be independent risk factors for death and progression of disease (in simple regression models when only adjusting for time period between diagnosis and rehab start), while age had no further additional statistical significant effect in our young study population. However, in the fully adjusted model, only lymphangiosis remained as a statistically significant predictor for conditional overall survival, while the analysis for disease-free survival identified lymph node involvement as well as lymphangiosis as significant predictors.

Differently than expected and described in previous studies $[7,8,22]$, infiltration of regional lymph nodes does not differ significantly between very young and young women in our cohort. This fact contradicts the assumption of later diagnosis in (very) young women but is supported by results of further studies [4, 23]. Evidently, patients with more advanced stage disease (N2/N3, T3/ T4) are characterised by poor 5-year survival. In our analyses (model 1), advanced lymph node involvement was statistically significantly associated with death and disease progression during follow-up, and advanced tumour growth showed a trend for significance (COS) and a significant effect on disease progression.

As observed in other studies, hormone receptor status in young women expresses itself differently and is associated with worse outcomes. Thus, very young women are more often oestrogen receptor negative and/or progesterone negative than women aged $>40$ years, as it has already been described in precedent studies $[7,8,13]$. Additionally, patients with hormone receptor negativity proved to be at increased risk for disease progression, death and lower survival, which has already been reported in former studies $[8,24,25]$, as an indication of the link between unfavourable tumour biology and poor survival in young women. Different to the hormone receptors, the expression of the growth factor HER2 is higher in young women below 40, which is comparable to other studies [26]. In our analysis, there is no difference in disease-free and overall survival comparing the groups with and without overexpression of HER2 and - moreover - there is an inconsistent evidence regarding the prognostic significance of HER2 [25, 27, 28].

In line with other study findings, young women show the unfavourable histological grade G3 as well as an increased lymphovascular invasion more frequently $[4,12$, $16,29]$. For both, poor histological grade and involvement of lymphatic vessels, COS as well as DFS take a worse course as has been shown in previous studies [2931].

In the current literature, non-uniform classification systems for tumour subtypes result in an inappropriate comparison between different studies. Our study, applying subtype categories by Brouckaert et al. [19] with 5 subtypes, shows considerable differences according to age.

Our study indicates that tumour subtypes significantly influence the outcome for women with non-metastatic breast cancer. Patients with B1 tumours and those with triple-negative disease proved to be subject to worse 5 -year conditional overall survival and disease-free survival rates (model 1 of Cox proportional regression models). When controlling for further clinical characteristics, the effect was still visible for the triple-negative subtype but lost its significance. Using the same classification system for tumour subtypes and different age groups, Brouckaert et al. [19] showed very similar results in frequency and survival. Another study focussing on women under 40 years with only 4 different subtypes deduced similar results as well [31].

Our study indicates that diagnosis at very young age compared to young age is a risk factor for worse 5-year survival, but the hazard risks from regression analyses fail to reach statistical significance. These findings coincide with those of many other studies $[2,3,9,15]$. Compared to similar studies, conditional 5-year overall survival with $95.5 \%$ and disease-free survival with $85.2 \%$ are much better in our cohort than in the study of Ito et al. [32] who reported conditional 5-year survival for 5-year survivors of breast cancer of $90.5 \%$. Our survival rates are higher than those of the cohort of Lian et al. [16] who reported an absolute breast cancer-specific survival rate for patients $\leq 40$ years of $84.9 \%$ and a disease-free survival for patients $\leq 40$ years of $62.5 \%$, as well as those of the study by $\mathrm{Yu}$ et al. [33] who reported conditional 5-year relative survival of $88.8 \%$ for patients with breast cancer 1 year 
after diagnosis. Considerable reasons for generally better outcomes in our study are the exclusion of metastasised breast cancer cases and the survivorship cohort (patients had survived already up to 2 years after diagnosis before they started with their rehab programme) in our study, in addition to a nationwide healthcare infrastructure and treatments with high guideline conformity in Germany [34].

Our study detects that there certainly is a link between higher prevalence of subtypes, which are associated with worse outcomes, in (very) young women. These findings correlate with the results of various other studies $[9,14$, 18].

In an additional analysis, we stratified molecular subtypes by age groups, similar to a comparable Chinese study [16], to discuss whether young age is an independent risk factor for women with breast cancer. Considering 2 different age groups with the same tumour subtype, no significant differences between the age groups could be shown in our study (data not shown). Astonishingly, there is a trend for women aged $<40$ years affected by subtype luminal B2 (a subtype with generally better outcome) to be at increased risk to die compared to women aged $\geq 40$ (HR 1.65, 95\% CI 0.49-5.12). Lian et al. [16] observed that for young women with luminal A and luminal B2 subtypes, young age could be an independent risk factor.

Partridge et al. [10] concluded based on a study with 3,401 HER2-positive breast cancer patients that age ( $\leq 40$ vs. $\geq 41$ years) was not a prognostic factor for disease-free or overall survival. In a more recent analysis, based on 17,575 women with stage I-III breast cancer (among them were 1,916 women $\leq 40$ years), very young women ( $\leq 40$ years) were more likely to die compared to the reference group (51-60 years; HR 1.9, 95\% CI 1.6-2.3) [35]. Comparable to the results of Lian et al. [16] and our analysis especially for subtypes with generally better outcomes, Partridge et al. [35] detected that for patients with luminal A disease, very young age might have a poor prognostic effect on mortality (HR 2.1, 95\% CI 1.4-3.2). The same was true for young women ( $\leq 40$ years) with luminal B disease, which had an increased risk to die (HR $1.4,95 \%$ CI 1.1-1.9) compared to the reference group (51-60 years).

Our study has several strengths and weaknesses worth mentioning. First of all, the large study population allowed stratification with respect to molecular subtypes with reasonable sample sizes. Second, although breast cancer in young women is rare, the rehab setting which is targeted at mothers with breast cancer predominantly attracts young women, thus allowing to describe differences between very young ( $<40$ years) and young breast cancer patients (40-54 years). Third, women from all over Germany who have been diagnosed and treated in many different settings take part in the rehab programme. Thus, our study population is most likely to be representative of young breast cancer patients in Germany. However, we did not aim for a centralised work-up of tumour specimens or a centralised second reading of images. Thus, there may be variation in the expertise of the local clinicians and pathologists leading to smaller deviations in the interpretation of the pathological and clinical findings.

Among the weaknesses of our study, we further have to mention that the exclusion of patients with metastatic disease and the recruitment of patients in a rehab setting may give an overly optimistic picture of survival, as only relatively healthy patients will take part in a rehab programme (confounding by indication). Moreover, only women who had finished their treatment were allowed to participate in the rehab programme; thus, the observed survival in our cohort represents conditional survival rather than absolute survival, and our results might be hampered by the survivorship bias as only women who had survived a certain time period since diagnosis were included in our study. However, we restricted our analysis to women with a maximum time period of 24 months between diagnosis and rehab start and adjusted for the time interval in our Cox proportional hazard models. Further, median follow-up time was 3.6 years with a maximum of 8 years since diagnosis. This follow-up period may be too short, given that breast cancer-associated deaths can occur also at a significantly later date. Recently, Haberland et al. [36] demonstrated that the excess mortality of breast cancer patients remains for a time span of $>10$ years.

In conclusion, our study revealed that with a maximum time period of 2 years since diagnosis, conditional 5 -year overall survival after non-metastatic breast cancer is as high as $95.5 \%$, and disease-free survival is $85.2 \%$. Young women in our study proved to be at lower risk to die in general, compared to other studies with the same age structure, which may be due to confounding by indication.

Differences between our 2 age subgroups were found in biological, pathological and clinical features. Especially those features associated with worse outcomes like oestrogen and progesterone negativity as well as lymphangiosis were observed more often in very young women. This translates to a higher proportion of supposedly more aggressive molecular subtypes such as HER2-like and triple-negative subtypes in very young women. The latter as well as nodal involvement and lymphangiosis proved to be significant risk factors for death during follow-up, but when adjusting for several clinical characteristics, only lymphangiosis remained as a statistically significant predictor of death during follow-up. 


\section{Acknowledgements}

We like to thank Klinik Ostseedeich for allowing scientific evaluation of the rehab programme. We are also grateful to all patients for taking part in our study. Their engagement makes our research possible and contributes to gaining knowledge about diagnosis, treatment, and prognosis of breast cancer in young women.

\section{Statement of Ethics}

The Ethics Committee of the University Lübeck approved the study protocol, and all women gave written consent for study participation. From 2010 on, written consent included not only the primary survey during the rehab but also the follow-up survey.

\section{Funding Sources}

This study was financed by the department of Obstetrics and Gynaecology, University Hospital of Schleswig-Holstein, and the Institute for Social Medicine and Epidemiology, University of Lübeck.

\section{Author Contributions}

A.W., D.F., and J.P. developed the research question. A.W., D.F., and A.K. made substantial contributions to the conception and design of the study. J.P. and A.W. analysed the data. J.P., A.W., F.H., and T.P. made substantial contributions to data interpretation. All authors reviewed, edited, and approved the final manuscript.

\section{Disclosure Statement}

The authors have no conflicts of interest to declare.

\section{References}

1 Barnes B, Kraywinkel K. Bericht zum Krebsgeschehen in Deutschland 2016. 2017. Available from: http://edoc.rki.de/docviews/abstract.php?id=4959.

2 Chung M, Chang HR, Bland KI, Wanebo HJ. Younger women with breast carcinoma have a poorer prognosis than older women. Cancer. 1996 Jan;77(1):97-103.

3 Gnerlich JL, Deshpande AD, Jeffe DB, Sweet A, White N, Margenthaler JA. Elevated breast cancer mortality in women younger than age 40 years compared with older women is attributed to poorer survival in early-stage disease. J Am Coll Surg. 2009 Mar;208(3):341-7.

4 Kheirelseid EH, Boggs JM, Curran C, Glynn RW, Dooley C, Sweeney KJ, et al. Younger age as a prognostic indicator in breast cancer: a cohort study. BMC Cancer. 2011 Aug;11(1): 383.

5 Fidler MM, Gupta S, Soerjomataram I, Ferlay J, Steliarova-Foucher E, Bray F. Cancer incidence and mortality among young adults aged 20-39 years worldwide in 2012: a population-based study. Lancet Oncol. 2017 Dec; 18(12):1579-89.

6 Banz-Jansen C, Heinrichs A, Hedderich M, Waldmann A, Dittmer C, Wedel B, et al. Characteristics and therapy of premenopausal patients with early-onset breast cancer in Germany. Arch Gynecol Obstet. 2012 Aug; 286(2):489-93.

7 Maggard MA, O'Connell JB, Lane KE, Liu JH, Etzioni DA, Ko CY. Do young breast cancer patients have worse outcomes? J Surg Res. 2003 Jul;113(1):109-13.

8 Lambertini M, Pinto AC, Ameye L, Jongen L, Del Mastro L, Puglisi F, et al. The prognostic performance of Adjuvant! Online and Nottingham Prognostic Index in young breast cancer patients. Br J Cancer. 2016 Dec; 115(12):1471-8.

9 Azim HA Jr, Partridge AH. Biology of breast cancer in young women. Breast Cancer Res. 2014 Aug;16(4):427.
10 Partridge AH, Gelber S, Piccart-Gebhart MJ, Focant F, Scullion M, Holmes E, et al. Effect of age on breast cancer outcomes in women with human epidermal growth factor receptor 2-positive breast cancer: results from a herceptin adjuvant trial. J Clin Oncol. 2013 Jul; 31(21):2692-8.

11 Anders CK, Hsu DS, Broadwater G, Acharya CR, Foekens JA, Zhang Y, et al. Young age at diagnosis correlates with worse prognosis and defines a subset of breast cancers with shared patterns of gene expression. J Clin Oncol. 2008 Jul;26(20):3324-30.

12 Colleoni M, Rotmensz N, Robertson C, Orlando L, Viale G, Renne G, et al. Very young women ( $[\{\mathrm{LT}\}] 35$ years) with operable breast cancer: features of disease at presentation. Ann Oncol. 2002 Feb;13(2):273-9.

13 Collins LC, Marotti JD, Gelber S, Cole K, Ruddy K, Kereakoglow S, et al. Pathologic features and molecular phenotype by patient age in a large cohort of young women with breast cancer. Breast Cancer Res Treat. 2012 Feb; 131(3):1061-6.

14 Morrison DH, Rahardja D, King E, Peng Y, Sarode VR. Tumour biomarker expression relative to age and molecular subtypes of invasive breast cancer. Br J Cancer. 2012 Jul; 107(2):382-7.

15 Fredholm H, Eaker S, Frisell J, Holmberg L, Fredriksson I, Lindman H. Breast cancer in young women: poor survival despite intensive treatment. PLoS One. 2009 Nov; 4(11):e7695.

16 Lian W, Fu F, Lin Y, Lu M, Chen B, Yang P, et al. The impact of young age for prognosis by subtype in women with early breast cancer. Sci Rep. 2017 Sep;7(1):11625.

17 Statistisches-Bundesamt: Todesursachen in Deutschland 2015. Gesundheit Fachserie 12 Reihe 4 2017:6.

18 Cancello G, Maisonneuve P, Mazza M, Montagna E, Rotmensz N, Viale G, et al. Pathological features and survival outcomes of very young patients with early breast cancer: how much is "very young"? Breast. 2013 Dec; 22(6):1046-51.

19 Brouckaert O, Laenen A, Vanderhaegen J, Wildiers H, Leunen K, Amant F, et al. Applying the 2011 St Gallen panel of prognostic markers on a large single hospital cohort of consecutively treated primary operable breast cancers. Ann Oncol. 2012 Oct;23(10):257884.

20 Holleczek B, Gondos A, Brenner H. periodR - an R package to calculate long-term cancer survival estimates using period analysis. Methods Inf Med. 2009;48(2): 123-8.

21 R Core Team. R: A language and environment for statistical computing. $\mathrm{R}$ foundation for statistical computing, Vienna, Austria. Available from: https://www.R-project.Org/. 2017.

22 Jenkins EO, Deal AM, Anders CK, Prat A, Perou CM, Carey LA, et al. Age-specific changes in intrinsic breast cancer subtypes: a focus on older women. Oncologist. 2014 Oct; 19(10):1076-83.

23 Grumpelt AM, Ignatov A, Tchaikovski SN, Burger E, Costa SD, Eggemann H. Tumor characteristics and therapy of elderly patients with breast cancer. J Cancer Res Clin Oncol. 2016 May;142(5):1109-16.

24 Dunnwald LK, Rossing MA, Li CI. Hormone receptor status, tumor characteristics, and prognosis: a prospective cohort of breast cancer patients. Breast Cancer Res. 2007;9(1):R6

25 Onitilo AA, Engel JM, Greenlee RT, Mukesh BN. Breast cancer subtypes based on ER/PR and Her2 expression: comparison of clinicopathologic features and survival. Clin Med Res. 2009 Jun;7(1-2):4-13.

26 Holleczek B, Jansen L, Brenner H. Breast cancer survival in Germany: a population-based high resolution study from Saarland. PLoS One. 2013 Jul;8(7):e70680. 
27 Nguyen PL, Taghian AG, Katz MS, Niemierko A, Abi Raad RF, Boon WL, et al. Breast cancer subtype approximated by estrogen receptor, progesterone receptor, and HER-2 is associated with local and distant recurrence after breast-conserving therapy. J Clin Oncol. 2008 May;26(14):2373-8.

28 Romond EH, Perez EA, Bryant J, Suman VJ, Geyer CE Jr, Davidson NE, et al. Trastuzumab plus adjuvant chemotherapy for operable HER2-positive breast cancer. N Engl J Med. 2005 Oct;353(16):1673-84.

29 Filleron T, Md FD, Kramar A, Spielmann M, Levy C, Fumoleau P, et al. Prognostic factors of young women ( $\leq 35$ years) with node positive breast cancer: possible influence on posttherapeutic follow-up. Bull Cancer. 2013 JulAug;100(7-8):22-9.
30 Sahoo PK, Jana D, Mandal PK, Basak S. Effect of lymphangiogenesis and lymphovascular invasion on the survival pattern of breast cancer patients. Asian Pac J Cancer Prev. 2014; 15(15):6287-93.

31 van der Hage JA, Mieog JS, van de Velde CJ, Putter H, Bartelink H, van de Vijver MJ. Impact of established prognostic factors and molecular subtype in very young breast cancer patients: pooled analysis of four EORTC randomized controlled trials. Breast Cancer Res. 2011 Jun;13(3):R68.

32 Ito $\mathrm{Y}$, Miyashiro I, Ito $\mathrm{H}$, Hosono S, Chihara D, Nakata-Yamada K, et al.; J-CANSIS Research Group. Long-term survival and conditional survival of cancer patients in Japan using population-based cancer registry data. Cancer Sci. 2014 Nov;105(11):1480-6.
33 Yu XQ, Baade PD, O’Connell DL. Conditional survival of cancer patients: an Australian perspective. BMC Cancer. 2012 Oct;12(1): 460.

34 Banz-Jansen C, Heinrichs A, Hedderich M, Waldmann A, Wedel B, Mebes I, et al. Are there changes in characteristics and therapy of young patients with early-onset breast cancer in Germany over the last decade? Arch Gynecol Obstet. 2013 Aug;288(2):379-83.

35 Partridge AH, Hughes ME, Warner ET, Ottesen RA, Wong YN, Edge SB, et al. Subtypedependent relationship between young age at diagnosis and breast cancer survival. J Clin Oncol. 2016 Sep;34(27):3308-14.

36 Haberland J, Baras N, Wolf U. Populationsbasierte Anteile geheilter Krebspatientinnen und -patienten in Deutschland. GMS Medizinische Informatik. Biometrie und Epidemiologie. 2019;15:1-11. 